\title{
A PERSPECTIVA DUALISTA DENTRO DO PENSAMENTO BACHELARDIANO
}

\author{
LA PERSPECTIVE DUALISTE DANS LA PENSÉE BACHELARDIENNE
}

Pedro Olivieri Fonseca ${ }^{1}$

\author{
http://dx.doi.org/10.52641/cadcaj.v6i4.536
}

\begin{abstract}
RESUMO: O presente trabalho se concentra na exposição dos conjuntos estruturais das ideias e dos aspectos estudados dentro do desenvolvimento de uma iniciação científica inserida no projeto de pesquisa do Prof. Dr. Marcos Alexandre Gomes Nalli “A Biopolítica como Biotécnica”, ofertada pelo programa instituicional de apoio à inclusão social pesquisa e extensão universitária, administrado pelo SEBEC e com a contemplação de bolsa pela Fundação Araucária. Resumidamente o subprojeto intitulado "A Perspectiva Dualista dentro do Pensamento Bachelardiano", se propôs a estudar e a pesquisar sobre os pormenores destas duas facetas contidas nas teorias e nos textos do autor Gaston Bachelard, e também buscar entender o movimento de desdobramento no pensamento do autor que o levou a desviar seu centro de interesses e pretensões investigativas de pesquisa de um direcionamento primeiramente diurno à ciência, à epistemologia e à gnosiologia com embasamento na psicanálise freudiana, para o período posterior e sua ultima fase de produção intelectual voltada à estética, tratada como a faceta noturna, ou, poética de Bachelard. Sobre esta transformação de interesse e consequentemente de pesquisa e produção, queremos propor a continuação de duas vias que cruzaram ambas as facetas desta dualidade, sendo elas a fenomenologia e psicologia.
\end{abstract}

Palavras-Chave: Dualidade, Fenomenologia Existencial, Fenomenotécnica, Psicologia.

RÉSUMÉ: Le présent travail se concentre sur l'exposition des ensembles structurels d'idées et d'aspects étudiés dans le cadre du développement d'une initiation scientifique insérée dans le projet de recherche du Prof. Dr. Marcos Alexandre Gomes Nalli «La biopolitique comme biotechnique», offert par le programme institutionnel de soutien à l'inclusion sociale, à la recherche et à l'extension universitaire, administré par SEBEC et avec une bourse de la Fundação Araucária. En bref, le sousprojet intitulé «La perspective dualiste dans la pensée bachelardienne», proposait d'étudier et de rechercher les détails de ces deux facettes contenues dans les théories et les textes de l'auteur Gaston Bachelard, et aussi de chercher à comprendre le mouvement qui se déploie dans pensée qui l'a amené à dévier son centre d'intérêts et ses intentions de recherche d'investigation d'une focalisation essentiellement diurne sur la science, l'épistémologie et la gnosiologie basée sur la psychanalyse freudienne, pour la période ultérieure et sa dernière phase de production intellectuelle centrée sur l'esthétique, traitée comme la facette nocturne, ou, la poétique de Bachelard. Concernant cette transformation de l'intérêt et, par conséquent, de la recherche et de la production, nous voulons proposer la poursuite de deux voies qui ont croisé les deux facettes de cette dualité, à savoir la phénoménologie et la psychologie.

Mots clés: Dualité, Phénoménologie existentielle, Phénoménotechnique, Psychologie.

\footnotetext{
${ }^{1}$ Graduado em Filosofia pela Universidade Estadual de Londrina (UEL)
} 


\section{Introdução}

\section{- A Luz da Ciência no Pensamento Diurno.}

O presente trabalho parte da perspectiva dualista da arte e da ciência, correspondente ao pensamento bachelardiano. Ao que tange sua parcela inicial de pesquisas e produções intelectuais, também chamada de parcela "diurna" pelos comentadores que fazem uso dessa metáfora do dia e da noite para dividir seus pensamentos e as suas ideias em dois períodos, corresponde ao seu âmbito investigativo da epistemologia, das possibilidades e maneiras de conhecimento (gnosiologia) e do modo em que a ciência avança e se desenvolve para melhor compreender a realidade na sua objetividade.

Completando e desenvolvendo seus trabalhos a respeito das condições de conhecimento objetivo, tendo como veículo principal para isso a ciência, ele elabora uma de suas teses principais "a psicanálise para o conhecimento objetivo", descrita na obra A Formação do Espírito Científico (1938), esta que tratava justamente da busca pelas condições mínimas necessárias para o tratamento dos dados objetivos única e exclusivamente dentro da ciência, eliminando os fantasmas e os modelos tradicionais que poderiam se tornar prejudiciais a verdadeira mentalidade científica.

O modelo de desenvolvimento científico, isto é, a maneira em que Bachelard acreditava que a ciência evolui era um reflexo de como ele a enxergava, tendo por base um dos conceitos principais denominado de "Obstáculo Científico", este que representa a constante atividade do espirito cientifico de evoluir, se desenvolver para não estagnar e nem retroceder. Com esta premissa, podemos explicar que as grandes evoluções deste espírito, em sua verdadeira mentalidade científica, acontecem pela superação dos obstáculos que se impõem sobre o a atividade de conhecer e de se aproximar da realidade na sua condição mais objetiva o possível.

Dentro da filosofia da ciência do séc XX, um dos principais nomes é o de Thomas Kuhn (1922-1996), graças aos conceitos contidos na obra A estrutura das Revoluções Científicas, de 1962, sendo o conceito chave principal o "paradigma". O paradigma é todo o conjunto de técnicas e teorias que embasam a atividade científica de uma determinada comunidade, sendo esta comunidade formada por cientistas que utilizam das mesmas ferramentas oferecidas pelo paradigma geral, para desenvolver suas pesquisas que visam explicar e prever o comportamento de alguns objetos através de uma série de experiências. Até essa parte da teoria de Kuhn, podemos dizer que não existem divergências no assunto de produção de conhecimentos científicos, levando 
em conta que no contexto geral desta época apenas os conhecimentos naturais (objetivos) eram legitimados como método científico, e os conhecimentos humanos ainda não tinham o status de ciência.

Deixando a semelhanças de lado, a divergência que surge é justamente no que tange a evolução e no desenvolvimento da ciência, porque no pensamento de Kuhn o que aparece são anomalias, que por sua vez perfuram as camadas do paradigma apontando no sinal de que ele não é mais suficiente para dar conto dos problemas que estão se apresentando nesta prática científica, surgido assim a crise que por sua vez culmina na quebra de um paradigma onde simultaneamente aparece um novo que surja para dar conta destas questões.

Já no pensamento bachelardiano, o que é mais fundamental para a evolução do espírito científico, faz parte do caminho de resolução e superação dos obstáculos, acontecendo através de rupturas, mas essas rupturas surgem pela atividade de retificação dos erros que são cometidos pelas facilitações de algum obstáculo, como no caso da adesão aos valores imediatos retirados premeditamente numa primeira experiência, a qual não sustenta o resultado esperado repetidas vezes e analisadas mais afundo. Sendo assim, é defendido que os mesmos objetos sejam submetidos várias e várias vezes as mesmas condições de experiências, no intuito de afastas as condições subjetivas de apreensão dele, e multiplicar os pontos de vista que ele pode ser explorado e estudado.

Nesse sentido, além de reconhecer a necessidade obvia de colocar os estudos científicos respectivamente inseridos dentro da sua contextualização história, a epistemologia do pensamento diurno de Bachelard, encaminhava passos que almejavam chegar a consolidação de um tratamento, que acreditará indispensável, para que se pudesse chegar a abordar a característica essencial dos objetos, que consiste na sua natureza polifacetada. Por isso, quanto mais repetidas vezes acontecesse uma experiência observada, maior seria o ângulo de amplitude das suas apreensões.

Então, ao mesmo tempo que ele se da conta do quanto uma apreensão do fenômeno, concentrada na subjetividade de alguém, pode trazer interpretações muito profundas e dissonantes com a realidade, ele também percebe que o mais importante não é o enfoque, e regramento do método científico, mas que o próprio método científico está em cima dos alicerces teóricos da fenomenologia, e é ai que ele desenvolve seu conceito de fenomenotécnica.

A fenomenotécnica no pensamento bachelardiano, representa a premissa epistemológica de que o objeto escolhido para os estudos, submetido a análises e experiências, bem como os resultados obtidos deste processo fazem parte do mesmo constructo. Sendo que, são inaugurados, desenvolvidos e só fazem sentido dentro da faculdade de pensamento e entendimento humano. Visto que os fenômenos observados, incluindo as experiências manipuladas pelas técnicas da ciência, não acontecem de maneira natural e independente, não são simplesmente encontrados na 
natureza, de maneira que o ato de observar não é isento neste processo, portanto o fenômeno observado é sempre uma criação do individuo em seu espaço, ou campo de observação.

De todo modo, assim como em Freud, a delineação de Bachelard do que constitui uma ciência parte da ideia de que toda teoria, para ser científica, deve estar atrelada a e depende de uma técnica específica que possibilite a emergência e a aproximação de um objeto. Todo objeto científico existe somente quando em ligação estreita com uma técnica que o fabrica e que torna factível e legítimo seu descobrimento posterior, além de garantir a coerência interna das doutrinas científicas (SISSON \& WINOGRAD, 2012, p. 4).

\section{- Considerações sobre o período noturno e a imaginação poética.}

Certamente não estaríamos nos esforçando e debruçando de uma maneira genuinamente criativa sobre o conjunto de ideias do autor, se pensássemos em entender a transformação e a passagem do período diurno para o seu pensamento noturno como uma ruptura tal qual aparece no processo de evolução e engrandecimento do espírito científico. Ainda mais se percebermos a sutileza da terminologia com que se refere o autor a tal entidade do conhecimento, pois se pararmos para pensar os conhecimentos humanos eram tratados na época de maneira periférica as demais áreas do saber, isso porque o que se apresentava como fonte segura e concreta do conhecimento real e efetivo era a ciência em seus métodos e comprovações empíricas.

Sem a consolidação de um status científico, os conhecimentos das áreas de humanas passavam a ser inferiorizados e eram nomeados como conhecimentos do espirito, enquanto os saberes que recebiam algum reconhecimento eram os considerados pelos métodos de análise e comprovação empírica, sendo somente passível de submeter ao método cientifico as teorias que pudessem ser comprovadas nas áreas de ciências da natureza.

Durante muito tempo, após a legitimação das áreas de conhecimentos da humanidade receberem o título de "Ciências Humanas", o qual não só a reconhecia a validade do seu conhecimento, mas a deixava em pé de igualdade epistemológica com as "Ciências Naturais", ou da natureza. O porém é que dentro de todo este processo, a comunidade científica, que era formanda na época somente por cientistas das áreas empíricas e concretas, acabou implementando dentro da ciências humanas o método que ela utilizava para investigação do real e para leitura dos dados colhidos, sendo assim a principal corrente que surgiu e teve representatividade dentro da recém nascida ciências humanas, foi o modelo qualitativo. Como aponta Rafael Prado na sua tese: "Nesse sentido, importa ressaltar que a pesquisa qualitativa surge no meio acadêmico nos anos 
1970, oriunda de críticas ao modelo investigativo positivista predominante à época nas Ciências Humanas, herdado das Ciências Naturais" (2013, pg 117 apud Schwandt, 2006).

Atualmente ainda surgem discussões sobre o encaixamento, ou enquadramento de diversas pesquisas, tais como a psicanálise que divide seus estudos parcialmente em aspectos metafisico, e parcialmente químico e biológico tratando sistema neural e da sua função clínica medicinal. Mas, que atualmente sem dúvidas já recebem o reconhecimento necessário para sua classificação como um saber científico.

Rompendo com determinado preconceito que sondava a mentalidade de sua época, o qual depositava toda sua fé no seguimento da "razão instrumental", assentando a credibilidade dos conhecimentos no pragmatismo das ciências naturais, Bachelard acaba por desviar deste caminho, e a tomar o seguimento tanto da filosofia quanto das demais particularidades dos conhecimentos humanos, como a literatura e poesia, valorizando o contato com produções textuais para o desenvolvimento de uma compreensão menos fechada e mais aberta em relação a realidade.

Neste período, ele trabalha com elementos da imaginação material, reconhecendo o caráter potencializador da matéria imaginada, retomando a estrutura base do pré-socratico Empédocles que defendia a composição material das coisas a partir da premissa dos quatro elementos (fogo, água, ar e terra), bem como a apropriação jungiana destes quatro elementos dentro da psicologia analítica, para a compreensão da estrutura psíquica da mente humana, onde Bachelard formula a poética dos quatro elementos.

Além disso ele também se apropria de teorias junguianas encontradas na sua psicologia analítica, tais como o conceito de inconsciente coletivo, que por sua vez acarreta numa concepção de arquétipos que atuam dentro dessa camada mais antiga, primitiva e profunda da mente humana, a qual todos nós compartilhamos, a diferença é que cada um de nós a apreendemos de um modo diferente. Mesmo com o inconsciente coletivo e os arquétipos que nele estão enraizados, Jung não elimina nem exclui a existência de um inconsciente particular daquela pessoa, sendo que esse inconsciente particular vai sendo construído ao longo da vida da pessoa enquanto o coletivo já está dentro dela de maneira herdada.

Esta exigência, para uma imagem poética, de ser uma origem psíquica teria, contudo, uma dureza excessiva se não pudéssemos encontrar uma virtude de originalidade nas variações mesmas que atuam sobre os arquétipos mais fortemente arraigados. Já que queríamos aprofundar, como fenomenólogo, a psicologia do maravilhamento, a menor variação de uma imagem maravilhosa deveria servir-nos para sutilizar nossas investigações. A sutileza de uma novidade reanima origens, renova e redobra a alegria de maravilhar-se (BACHELARD, 2001, p.3). 
Vemos que no pensamento bachelardiano, os arquétipos aparecem carregados dos significados simbólicos de conhecimentos culturais dos antepassados, e é dentro da tarefa de identificação da atividade deles dentro do nosso aparelho psíquico, que nos é dada a oportunidade de conhecer determinado movimento de interpretação (assimilação) e de externalização (expressão) que acontecem no nosso interior da nossa personalidade e do nosso ser.

Os tipos psicológicos definidos por Jung eram divididos primeiramente na identificação da atividade psicológica, podendo apresentarem uma atividade introvertida ou extrovertida. A segunda divisão feita, tem base nas funções que aquele aparelho apresenta, sendo elas: pensamento, sensação, sentimento e a intuição. Claro que os aparelhos psíquicos, nas suas complexidades, em algum momento podem variar de alguma função a outra, mas a identificação consiste em decifrar qual dessas funções estão mais acentuadas naquele indivíduo.

O símbolo arquétipo de cada uma das funções, bem como da suas maneiras de apresentação ativa, estão presentes num aqueduto muito profundo da psique humana, sendo que todos os aparelhos psíquicos recebem essa herança na sua composição ancestral, mas eles também apresentam as inclinações e algumas tendências advindas de um comportamento mental que se encaixa em determinada tipologia ligada a algum dos quatro elementos. Em outras palavras, determinado aparelho psíquico apresenta correspondência nas características que são simbolicamente representadas em algum dos quatro elementos da matéria.

Transformando a leitura e sua atividade de compreensão em uma atividade muito mais abrangente, a partir da ressalva de que a leitura pode servir como canal de transposição para percepção de mundo daquela pessoa que escreve em direção ao leitor. Com isso, podemos investigar não só a pluralidade de apreensões fenomenológicas sobre determinado conceito, ou, experiência, que seria apreendidas a partir da parcela subjetiva de cada indivíduo, incluindo sua relação corpo e mente, dentro do contato com algum conceito, ou, experiência que resulte não só numa mera apreensão, mas, que ela ocorra sobre a fluidez de um dinamismo imaginativo e criador, que acentue, construa e desenvolva uma imagem singular sobre aquilo que foi contemplado, e que posteriormente aquilo sirva como material criativo para pessoa (re)produzir e externalizar sua perspectiva.

\section{A função da arte dentro da identificação de um significado pessoal para os sonhos.}


Abre-me o sonho

Para a loucura a tenebrosa porta, Que a treva é menos negra que esta luz. O terror desvaria-me, o terror De me sentir viver e ter o mundo Sonhado a laços de compreensão $\mathrm{Na}$ minha alma gelada (Pessoa, 1988, p.60).

Assim como nos sonhos, na arte também existe uma discussão sobre o seu significado e a sua importância. Este trabalho se propõe a conceber tanto a arte quanto o sonho, como fontes de uma interpretação pessoal da realidade, seja de um artista ou de um sonhador, ambos estão diante da expressão de uma pulsão interna tão grande que se projeta para o exterior.

As vezes não conseguimos chegar ao compreendimento, ou a consciência plena da fonte e da essência de tal pulsão instigadora, porém, toda a sua construção e contexto pode nos apresentar sinais importantes para tentarmos apreendê-la de alguma forma. A questão é que nem sempre podemos mapear o surgimento desta pulsão criativa dentro do aparelho psíquico.

Contudo, ao comparar as manifestações artísticas com as manifestações oníricas do nosso pensamento, podemos dizer que com certeza a criatividade está presente nos dois processos, uma vez que elas encontrem caminhos para a realização de um desejo, ou mesmo um caminho para a fuga da realidade em que aquela pessoa se encontra. Portanto, tanto a arte quanto o sonho, podem nos oferecer elementos completamente novos que só existem porque alguém em sua introspecção criativa, os geriu e deu-lhes vida.

Neste movimento de aproximação entre o universo da arte e dos sonhos, chegamos a um ponto que acreditamos ser no mínimo curioso, trata-se de nos esforçar em trazer aspectos artísticos para dentro dos sonhos, a fim não só de enriquece-los em matéria prima, mas também de conseguir e facilitar a identificação dos conteúdos que estão presentes nesse sonho.

Acreditamos que ao interligar aos objetos oníricos, expressões artísticas, eles brotam de maneira mais fluida dentro da consciência do sonhador, aparecendo mais nitidamente e se 
apresentando de maneira menos tensa. Com a conexão artística entre os conteúdos e significados dos sonhos, podemos ampliar a pequena parcela deste sonho, que ainda tenha permanecido na consciência, além facilitar e propor mais fluidez nesta corrente de matéria inconsciente quese desagua na consciência.

Utilizando dos meios artísticos para mergulhar no profundo oceano do inconsciente, além de enriquecer a identificação dos signos e símbolos que estão presentes em todo o inconsciente, também podemos facilitar a identificação de traços pessoais e particulares que fazem toda a diferença quando tentamos entender o processo de criatividade de um aparelho psíquico.

Com isto, estamos dizendo que as ramificações artísticas não só existem pela presença de uma singularidade no artista, a qual o possibilita perceber e enxergar a realidade com um olhar próprio, e por isso retrata a realidade de uma maneira que na maioria das vezes não é a mesma maneira que temos enxergado, seja qual for a ferramenta que ele utilize para manifestar isso. Como também, os canais artísticos podem ser altamente prestativos quando queremos perceber aonde estão aparecendo as características singulares num sonho, acreditando que podemos utilizar das riquezas da arte para entender as representações que aparecem no sonho, as quais por sua vez estão conectadas de alguma forma com a faculdade criativa do intelecto.

Concluindo a ideia que se apresenta acima, resumindo-a em dizer que tanto o sonho quanto a arte são fundamentais para continuar fomentando a criatividade do ser humano, pois sem elas estaríamos estagnados num padrão universal tanto de comportamento quanto de pensamento e visão de mundo. Em outras palavras, é graças as múltiplas expressões do individual e da diversidade subjetiva que existe a arte, por conseguinte, existe a representação desta parcela realmente singular dentro do inconsciente, inserida em toda a complexidade que compõe os sistemas psíquicos.

As pulsões do inconsciente se manifestam tanto nos períodos acordados, quanto nos sonhos, sendo que nos sonhos se torna uma tarefa mais difícil de decifrar o sentido e significado da pulsão manifestada, por diversos fatores como: a repressão que ocorre na sua transposição para consciência, podendo levar a esquecimentos ou bloqueios de determinadas partes chave dos sonhos, a vergonha e a censura durante o relato do sonho, entre outras dificuldades que podem surgir nessa tarefa de decifrar o sonho.

As pulsões inconscientes que se manifestam no período desperto da pessoa, isto é, quando ela está acordada, assim como no sonho, tem o objetivo de ser extravasada, descarregada e trazer satisfação e alívio ao sistema psíquico. Entretanto, a realização dessa descarga pulsional pode 
acontecer de maneira inconsciente mesmo durante os períodos de consciência, em outras palavras, o conteúdo principal daquela pulsão pode ser externalizado sem que aquela pessoa se de conta dele.

Neste sentido, podemos dizer que aquela pessoa nem se quer teve a liberdade de escolher extravasar ou reprimir a pulsão vinda do seu inconsciente, pois ela era tão intensa que acabou encontrando sua externalização independente da vontade, ou da percepção daquela pessoa. Em todo caso, é necessário que ela tome consciência da força e do direcionamento de sua própria pulsão, para conseguir optar por reprimi-la ou manifestá-la da maneira que considerar mais adequada. Deixando sua condição de passividade em relação ao inconsciente, para tomar uma postura decisiva em relação a suas atitudes, de modo que as manifestações da matéria e das pulsões do seu inconsciente possam aparecer e serem percebidas para serem moduladas.

Então, a proposta de utilização das diversas possibilidades de expressão artística para identificação dos conteúdos latentes do sistema psíquico, além de ser elaborada pelo interesse investigativo de entender os momentos mais elevados de criatividade daquela mente, também admite que nem sempre as pulsões inconscientes aparecem na superfície de uma personalidade como uma qualidade ou um aspecto positivo que deve ser apreciado genuinamente pela sua beleza, pelo contrário, muitas vezes elas representam sombras e abismos de escuridão que aquela pessoa carrega dentro de si, as quais por vezes se acentuam e sobressaltam nos traços individuais de cada existência.

E é por isso também que aderimos as expressões artísticas não só para identificar, mas para também vestir-se delas nos momentos de exteriorização e transposição da matéria e das pulsões do inconsciente, a fim de que elas sejam apreendidas primeiramente, para que depois do momento que a consciência se de conta delas e da sua existência, busque embelezar e enriquecer as suas formas de expressão e aparição, tornando-la mais leve, assim como a própria existência da sua personalidade, do seu inconsciente de maneira geral do seu "eu". Podemos dizer que não só o sonho, mas também a arte, utilizam como matéria prima os conteúdos do inconsciente, para transfigurá-los e re-simbolizar eles, trazendo para sua capacidade criativa o artífice de escavar camadas mais profundas de psique.

Camadas que estão contidas em qualquer aparelho psíquico, e que contudo, para cada uma destes, ela aparecerá dentro de uma representação diferente, o que quer dizer que a singularidade está nesse movimento de identificação própria das suas pulsões, bem como no momento em que aquela pessoa traz à tona e coloca para fora está parte de si, a parte dela que carrega no mais profundo do seu ser. 
Poderíamos, utilizando esta construção de raciocínio, dizer poeticamente que os elementos pulsionais do inconsciente são obscuros, profundos e complexos, sendo que quando iluminamos eles com a nossa consciência eles já não são os mesmos de quando viviam na noite, isto é, quando as matérias noturnas aparecem no dia, isso acontece sempre por uma mediação simbólica, ou figurativa daquele conteúdo.

Quando as cargas inconscientes são muito grandes, hora ou outra elas encontram uma representação que também tenha uma carga muito forte naquele sistema e que esteja constantemente presente na sua memória, ou que de alguma forma seja constante em seus pensamentos. Então, para que esta pulsão chega à consciência, é necessário percorrer um único meio, e a única abertura que se apresenta para a transposição saindo do inconsciente em direção a consciência, é possível somente pela associação deste impulso a alguma representação que possua uma carga acentuada, de modo que ela se mantem constante na mente. Portanto, a pulsão inconsciente se externaliza e se descarregar através da sua própria associação a uma representação que esteja fortemente presente na mente.

Pelo menos isso é o que podemos observar dentro das teorias tradicionais da psicanálise originária de Freud, a qual se acentua durante o primeiro período de suas conjecturas sobre a mente humana, denominado de "Primeira Tópica". Esse constructo sem dúvidas foi de muita importância e de muito avanço para a área da psicologia, da neurociência e das demais áreas que buscam compreender as estruturas da mente. Porém mesmo reconhecendo suas riquezas e a revolução que suas teorias trouxeram nestas áreas do conhecimento, ainda foi necessário que fizéssemos recortes para aproveitar o que acreditamos estar engradecendo nosso trabalho, do modo que se nos aproximássemos muito a risca da sua tese psicanalítica, seria difícil continuar e concluir nossa proposta inicial, visto que o trabalho que teríamos em explica-la em pormenores não seria pouco. Lembrando também que quando tratamos dos aparelhos psíquicos não podemos abandonar a complexidade e a profundidade de suas estruturas, que por sua vez também se refletem nas teorias, teses e pesquisas que tornam a mente um objeto e um objetivo de estudo.

Dentro da difícil tarefa, de identificar as forças inconscientes presentes tanto nos sonhos, quanto na atividade lucida do cérebro, podemos contar com um viés artístico, uma visão artística que nos ofereça uma perspectiva estica sobre o mundo, que acentue a beleza das coisas, uma mentalidade que nos ofereça a lapidação do modo próprio de vida do nosso "eu" idiossincrático. Para assentar, embasar sustentar o chão sobre o qual queremos colocar este debate individual dos aspectos singulares do ego, para com a estrutura comum e compartilhada em todas as mentes, usaremos primordialmente sobre as considerações singulares do ser, os escritos bachelardianos, 
bem como seus comentadores e também algumas das leituras que ele teve contato e que lhe inspiraram a estudar a psicologia para tentar compreender as parcelas mais subjetivas da mente, tendo contato inicialmente com as teorias da psicanálise de Freud e trabalhando elas na sua perspectiva epistemológica do conhecimento, posteriormente conhecendo um dos alunos de Freud, o qual tiveram um rompimento mais além, responsável por categorizar a psicologia analítica, chama Carl Gustav Jung. Bachelard, incorporando premissas dessas duas teorias dentro da sua filosofia sobre os conceitos fenomenológicos de imaginação, noo desenvolvimento de algumas faculdades que podem corroborar para a identificação destes aspectos mais subjetivos de cada indivíduo dentro da sua criatividade.

\section{Referências Bibliográficas:}

BACHELARD, Gaston. O Direito de Sonhar. Trad. José Américo M. Pessanha. 4ª ed. São Paulo: Bertrand, 1994.

Poética do Devaneio. Trad. Antonio de Pádua Danesi $3^{a}$ ed. São Paulo: Martins Fontes. 2001.

, Psicanálise do Fogo. Trad. Paulo Neves. 2.a ed. São Paulo: Martins Fontes, 1999.

, O Ar e os Sonhos: ensaio sobre a imaginação do movimento. Trad. Antonio de Pádua Danesi 2. ${ }^{a}$ ed. São Paulo: Martins Fontes, 2001a.

A terra e os devaneios da vontade: ensaio sobre a imaginação das forças. Trad. Maria Ermantina Galvão. 2aed. São Paulo: Martins Fontes, 2001b.

A terra e os devaneios repouso: ensaio sobre a imagens da intimidade. Trad. Paulo Neves. 2. ${ }^{a}$ ed. São Paulo: Martins Fontes, 2003.

BASTISTA DE OLIVEIRA, L. Psicanálise, poética e epistemologia: a contribuição de Gaston Bachelard. 1997. 86f. Dissertação (Dissertação em filosofia) Pontifícia Universidade Católica de São Paulo - SP. ed. Uel, 1999.

LESSA, Machado Jardin \& NOVAES, De Sá Roberto. A relação psicoterapêutica na abordagem fenomenológico-existencial. Jul. 2006, Lisboa. Disponível em: < http://www.scielo.mec.pt/pdf/aps/v24n3/v24n3a13.pdf> Acesso: 21/07/2020.

PESSANHA, J. A. M. GASTON BACHELARD O Direito de Sonhar, in: BACHELARD, G. O Direito de Sonhar $4^{a}$. ed. São Paulo: Bertrand, 1994. Disponível em: 
< $\underline{\text { https://filosoficabiblioteca.files.wordpress.com/2013/11/bachelard-o-direito-de-sonhar.pdf }>}$ Acesso: 15/11/2019.

PESSOA, Fernando. Primeiro Fausto. 1988. Disponível em: http://www.dominiopublico.gov.br/download/texto/pe000005.pdf . Acessado: 01/07/2020.

PRADO, Rafael Auler de Almeida. Linguagem poética e clínica fenomenológica existencial: aproximações a partir de Gaston Bachelard. Dez. 2012. Tese defendida na Universidade Católica de Pernambuco Disponível em:

$<$ http://pepsic.bvsalud.org/scielo.php?script=sci_arttext\&pid=S1809-

068672012000200012\&lng=pt\&nrm=iso >. Acesso: 21/07/2020.

RIBEIRO, Sidarta. Sonho, memória e o reencontro de Freud com o cérebro. Rev. Bras. Psiquiatr. [online]. 2003, vol.25. Disponível em: < http://www.scielo.br/pdf/rbp/v25s2/a13v25s2.pdf $>$ Acesso: 15/02/2020.

ROSIMERI, Bruno Lopes. Os Sonhos na concepção de Freud. Psicologado, 2012. Acessado em 31/03/2020. Disponível em: < https://psicologado.com.br/abordagens/psicanalise/ossonhos-na-concepcao-de-freud>

SISSON, Nathalia \& WINOGRAD, Monah. Bachelard e Freud: fenomenotécnica e psicanálise. Arquivos Brasileiros de Psicologia [en linea] 2012. Disponível em: <http://www.redalyc.org/articulo.oa?id=229025830007>. Acesso: 14/04/2019. 